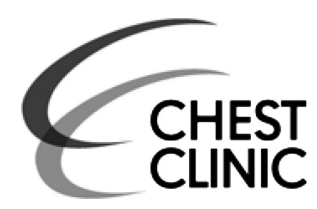
CLHEST

epartment of General Paediatrics, Children's Hospital for Wales, Cardiff, UK ${ }^{2}$ Paediatric Emergency Department, Bristol Royal Hospital for Children, Bristol, UK

${ }^{3}$ Academic Department of Emergency Care, University of the West of England, Bristol, UK

${ }^{4}$ Department of Emergency Medicine, Cork University Hospital, Cork, Ireland ${ }^{5}$ Department of Paediatric Respiratory Medicine, Children's Hospital for Wales, Cardiff, UK

${ }^{6}$ Institute of Molecular and Experimental Medicine, Cardiff University, School of Medicine, Cardiff, UK

\section{Correspondence to}

Dr Colin V E Powell, Department of Child Health, Children's Hospital for Wales, Cardiff; Institute of Molecular and Experimental Medicine, Cardiff University School of Medicine, Cardiff CF14 4XW, UK; powellc7@cardiff.ac.uk

Received 12 July 2014 Revised 25 September 2014 Accepted 26 September 2014 Published Online First 10 October 2014 2015;70:88-91.

\title{
Which intravenous bronchodilators are being administered to children presenting with acute severe wheeze in the UK and Ireland?
}

\author{
I Morris, ${ }^{1}$ M D Lyttle, ${ }^{2,3}$ R O'Sullivan, ${ }^{4}$ N Sargant, ${ }^{2}$ I J M Doull, ${ }^{5}$ C V E Powell, ${ }^{1,6}$ \\ on behalf of the PERUKI network
}

\section{ABSTRACT}

During a prospective 10-week assessment period, 3238 children aged 1-16 years presented with acute wheeze to Paediatric Emergency Research in the UK and Ireland centres. 110 (3.3\%) received intravenous

bronchodilators. Intravenous magnesium sulfate $\left(\mathrm{MgSO}_{4}\right)$ was used in $67(60.9 \%)$, salbutamol in $61(55.5 \%)$ and aminophylline in $52(47.3 \%)$ of cases. In 35 cases $(31.8 \%)$, two drugs were used together, and in 18 cases $(16.4 \%)$, all three drugs were administered. When used sequentially the most common order was salbutamol, then $\mathrm{MgSO}_{4}$, then aminophylline. Overall, 30 different intravenous treatment regimens were used varying in drugs, dose, rate and duration.

\section{INTRODUCTION}

Episodes of acute severe wheezing represent a significant proportion of emergency department (ED) presentations and hospital admissions. ${ }^{1}$ Initial strategies of inhaled $\beta_{2}$ agonists, ipratropium bromide and corticosteroids have a good evidence base, but that for second-line agents including intravenous salbutamol, aminophylline or magnesium sulfate $\left(\mathrm{MgSO}_{4}\right)$ is less clear. ${ }^{2}$

Our aim was to evaluate the management of acute wheezing illness in EDs in the UK and Ireland by determining the frequency and demographic details of presentations of wheeze and examining the use of intravenous bronchodilators.

\section{METHODS}

This was a prospective observational multicentre service evaluation of the management of acute severe wheezing in EDs within the Paediatric Emergency Research in the UK and Ireland (PERUKI) network. PERUKI is a research collaborative of paediatric-specific and mixed adult and paediatric EDs with an annual census of over 1 million childhood visits (see the Acknowledgements section). A continuous data set was collected at each site across a 10-week period commencing in March 2013 which were:

1. Screening denominator data

All children aged from 12 months to 16 years who presented with wheeze were screened, and a proforma was completed for all patients.

2. Those receiving intravenous treatment

For all presentations resulting in intravenous therapy, a more detailed proforma exploring severity of illness and management decisions was completed.

Data were double entered and errors addressed and analysed using SPSS V.21.

\section{RESULTS}

Twenty-four centres contributed to the evaluation. Two sites were unable to collect detailed screening data of all those presenting other than the numbers presenting, and one of those centres was able to provide detailed data on those children who received intravenous treatment (table 1). The remaining centres delivered $100 \%$ capture rate of data for all those children presenting with acute wheeze during the data collection period.

\section{Screening denominator data}

During the evaluation 3238 children presented with acute wheeze (2008 male; 62\%) with a median (IQR) age of $3(1-5)$ years. It was the first episode of wheeze for $692(21.3 \%)$ children. A total of $110(3.3 \%)$ children received intravenous treatment. Intravenous rate varied among sites between $0 \%$ and $19.4 \%$ (table 1). Children who received intravenous treatment had significantly lower mean $\mathrm{O}_{2}$ saturations (91.5\% (SD 5.5)) compared with those who did not $(95.8 \%$ (SD 3.3), mean difference $4.3 \%$ (95\% CI for the difference $3.2 \%-5.4 \%), \mathrm{p}<0.001$; figure 1). Females $(5.5 \%)$ were more likely to receive intravenous treatment compared with males $\left(2.6 \% ; \chi^{2} 6.5 ; \mathrm{p}<0.001\right)$. No nebulised $\mathrm{MgSO}_{4}$ was reported being used.

\section{Those receiving intravenous treatment}

The 110 children had a median age of 4 years, 63 (57.3\%) were females and $1311.8 \%$ presented with wheezing for the first time. $\mathrm{MgSO}_{4}$ was the most commonly used intravenous bronchodilator, followed by salbutamol and then aminophylline. Details of the most common doses, and dose ranges for each agent are presented in table 2 . The terms 'load' and 'bolus' appeared to have been used interchangeably, so we used the term 'bolus' if it was not followed by an infusion and used the term 'load' (whatever the dose) if it was followed by an infusion.

\section{Drugs used}

$\mathrm{MgSO}_{4}$ was only administered as a bolus $(\mathrm{n}=67)$; there was no use of a continuous infusion. Repeated doses of $\mathrm{MgSO}_{4}$ were given in 4 cases; 
Table 1 Type of emergency department with annual attendance rates along with numbers seen during the data collection period and rate (\%) of intravenous treatment administered per centre

\begin{tabular}{|c|c|c|c|c|}
\hline ED type & $\begin{array}{l}\text { Attendances } \\
\text { per year }(n)\end{array}$ & $\begin{array}{l}\text { Numbers } \\
\text { screened (n) }\end{array}$ & $\begin{array}{l}\text { Intravenous } \\
\text { rate }(\mathrm{n})\end{array}$ & $\begin{array}{l}\text { Intravenous } \\
\text { rate }(\%)\end{array}$ \\
\hline Stand alone CED & 47500 & 335 & 13 & 3.9 \\
\hline Stand alone CED & 24500 & 93 & 18 & 19.4 \\
\hline Stand alone CED & 35000 & 245 & 4 & 1.6 \\
\hline Stand alone CED & 31500 & 138 & 6 & 4.3 \\
\hline Stand alone CED & 30000 & 109 & 3 & 2.8 \\
\hline Stand alone CED & 34000 & 181 & 7 & 3 \\
\hline Stand alone CED & 41000 & 246 & 4 & 1.6 \\
\hline Stand alone CED & 45000 & 204 & 9 & 4.4 \\
\hline Stand alone CED & 58500 & $\begin{array}{l}204 \text { (no data } \\
\text { collected) }\end{array}$ & No data capture & Not known \\
\hline Stand alone CED & 30000 & 96 & 3 & 3.1 \\
\hline Stand alone CED & 45000 & 107 & 6 & 2.8 \\
\hline Stand alone CED & 50000 & 180 & 3 & 1.7 \\
\hline Mixed ED with AVS & 36000 & 117 & 3 & 2.6 \\
\hline Mixed ED with AVS & 33500 & 166 & 5 & 3 \\
\hline Mixed ED with AVS & 24000 & 86 (no data collected) & 2 (data collected) & 2.3 \\
\hline Mixed ED with AVS & 23000 & 89 & 5 & 5.6 \\
\hline Mixed ED with AVS & 26500 & 141 & 10 & 4.1 \\
\hline Mixed ED with AVS & 18000 & 6 & 0 & 0 \\
\hline Within mixed ED with AVS & 25500 & 43 & 1 & 2.8 \\
\hline Within mixed ED with AVS & 24000 & 17 & 1 & 2.8 \\
\hline Within mixed ED with AVS & 20000 & 60 & 1 & 1.7 \\
\hline Within mixed ED with AVS & 35000 & 104 & 5 & 4.8 \\
\hline $\begin{array}{l}\text { Fully separate department adjacent to adult } \\
\text { unit but shares resuscitation facilities }\end{array}$ & 38000 & 141 & 2 & 1.4 \\
\hline General ED with CED open 10.00-22.00 & 19500 & 130 & 0 & 0 \\
\hline TOTAL & & 3238 & 110 & 3.33 \\
\hline
\end{tabular}

AVS, audiovisual separation; CED, children's emergency department; ED, emergency department.

one immediately after the first load and the others 2,8 and $12 \mathrm{~h}$ later.

For salbutamol $(n=61)$, a load followed by an infusion was the most common regimen, occurring in 40/61 (65.7\%) of cases. Ten (16.4\%) children had an infusion only and $11(18 \%)$ only a bolus. There were 22 variations of bolus/load dose and duration.

The most common aminophylline regimen was a load followed by an infusion 44/52 (85\%); 5 (9.6\%) children had a bolus only and 3 children received an infusion with no load (table 2).

\section{Treatment regimen}

A total of 57/110 (52\%) were managed with one agent only, 35/ $110(32 \%)$ with two agents and 18/110 (16\%) were managed with all three agents. $\mathrm{MgSO}_{4}$ was used with other agents in 53 of $110(48.2 \%)$ cases and was administered concurrently in 10/ $53(18.9 \%)$. When used sequentially it was the first drug given in $19 / 43(36 \%)$ cases. Salbutamol was used with other agents in $43 / 110$ (39\%) and was used concurrently in 7/43 (16.3\%) cases. When used sequentially it was the first drug of choice in $18 / 36$ $(50 \%)$ of cases. Aminophylline was used with other agents in $28 / 110(25.5 \%)$ cases and was used concurrently in 5/28 $(17.9 \%)$ cases. When used sequentially it was the first drug given in 10/23 (43.5\%) cases. When all three drugs were used, the first-line agent was most commonly salbutamol 9/18 (50\%), others used $\mathrm{MgSO}_{4}$ first line $7 / 18$ (38.8\%), with aminophylline being the least common first-line choice in $2 / 18(11.1 \%)$. The most common order of agents used was salbutamol, $\mathrm{MgSO}_{4}$ and then aminophylline in 10/18 (55.6\%) cases.

\section{Weaning off intravenous treatment}

Where infusions were used their duration varied from 4 to $72 \mathrm{~h}$. Weaning involved halving the dose before stopping in half the cases, the remainder simply stopped directly from the initial dose when deemed to be clinically unnecessary.

\section{Disposition}

A total of $35 / 110(31.8 \%)$ were managed on an inpatient or observation ward, 66/110 (60.0\%) on a Paediatric High Dependency Unit (PHDU) and nine $(8.2 \%)$ on a Paediatric Intensive Care Unit where seven children were intubated and one child died. Non-invasive ventilation was used in $7 / 110$ (6.4\%). Most patients who received $\mathrm{MgSO}_{4}$ alone were managed on an inpatient or observation ward, whereas most who received either aminophylline or salbutamol alone were managed on a PHDU.

\section{DISCUSSION}

We have demonstrated wide variation in the clinical management of acute severe wheeze across the UK and Ireland, with variability of the choice of treatment strategy in terms of drug combinations, dosing and weaning strategies. The small numbers in our study did not allow direct comparison between individual units nor could we explore the thresholds and rationale behind the initiation of intravenous treatment. However, those children 
Figure 1 Oxygen saturation in air at presentation for the children presenting with wheeze and administration of intravenous bronchodilator therapy.

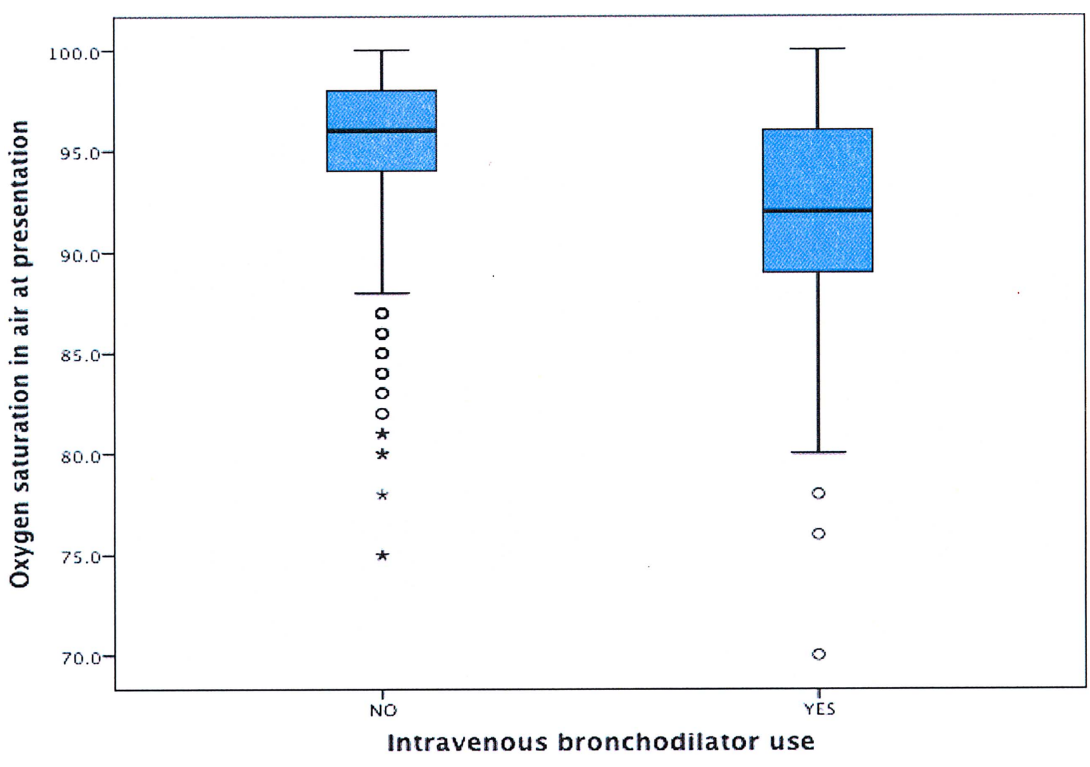

receiving intravenous treatment had lower oxygen saturations in air at presentation, compared with those who did not get intravenous treatment thus reflecting their severity (figure 1).

It is well recognised that clinicians vary in their practice when treating acute wheezing. While practice in mild to moderate disease is broadly similar, marked differences for treating more severe cases are recognised. ${ }^{3}$ This is likely due to the paucity of evidence and conflicting literature underlying the management of severe wheeze in childhood.

Cochrane reviews considering the benefit of intravenous salbutamol included few good-quality studies in children, and there was insufficient evidence to support the use of intravenous $\beta_{2}$ agonists in acute asthma. Despite its common use, the safest and most effective doses for intravenous salbutamol are unknown. In our study, the greatest variation in management was in doses of salbutamol administered. ${ }^{2}$ Cochrane reviews of intravenous aminophylline in adults and children fail to demonstrate any clinical benefit over intravenous $\beta_{2}$ agonists. However, paediatric studies have suggested hastened recovery, a reduced need for ventilation in severe cases, significant reduction in length of hospital stay and improvements in pulmonary function. UK guidelines state that intravenous aminophylline should be reserved for the most severe cases unresponsive to maximal bronchodilators and steroids. $^{2}$ Current UK recommendations acknowledge that intravenous $\mathrm{MgSO}_{4}$ is safe, although its efficacy in children has not been established. ${ }^{2}$ Meta analyses suggest improvements in short-term pulmonary function and clinical symptoms when used in combination with inhaled bronchodilators and steroids with a greater effect in children than in adults. ${ }^{4}$
Single agents were used in 52\% of cases, two agents in 32\% and all three in $16 \%$. There is currently no evidence to inform an optimal approach, and at present, none of the widely used guidelines offers direction for practice in terms of combinations and sequences of administration of these agents. There were differences in disposition for intravenous drug administration and monitoring. While most patients received care on PHDU, one-third were managed in observation or inpatient wards. This may have reflected the severity of the exacerbation but it may be that boluses of drugs with no infusion allow children to be nursed on a ward, whereas continuous infusions require higher level care.

A limitation of the evaluation was that we were unable to obtain data from some of our participating centres but the majority of presentations of wheeze were males, under the age of 5 years, and many were recurrent attendees. There was a preponderance of girls receiving intravenous bronchodilators. This accords with previous BTS audits of paediatric wheeze ${ }^{5}$ suggesting face validity of our data. We did not collect data on complications of treatment. This was a pragmatic evaluation examining what actually happened; we did not define severe wheezing nor was the study designed to decide whether it was appropriate to administer the intravenous treatment.

Our study has demonstrated variation in practice across the UK and Ireland in the management of children with acute severe wheeze. There is an urgent need for randomised trials to determine the efficacy, safety profile and optimal dosing for commonly used intravenous therapies, aiming for a clear evidence base for the management of acute severe wheeze in children.

Table 2 Intravenous treatments $(n=110)$

\begin{tabular}{llll}
\hline Drug & Cases used & Most common dose & Dose ranges \\
\hline $\mathrm{MgSO}_{4}$ & $67(60.9 \%)$ & $\begin{array}{l}\text { Bolus: } 40 \mathrm{mg} / \mathrm{kg} \text { over } 20 \mathrm{~min}(50.7 \%) \\
\text { Infusion: N/A }\end{array}$ & $\begin{array}{l}\text { Bolus: } 5-54 \mathrm{mg} / \mathrm{kg} \text { over } 20-30 \mathrm{~min} \\
\text { Infusion: N/A }\end{array}$ \\
Salbutamol & $61(55.5 \%)$ & $\begin{array}{l}\text { Bolus/load: } 250 \mu \mathrm{g}(33.3 \%) \text { over } 5-15 \mathrm{~min} \\
\text { Infusion: } 1 \mu \mathrm{g} / \mathrm{kg} / \mathrm{min}(68 \%)\end{array}$ & $\begin{array}{l}\text { Bolus/load: } 2-15 \mu \mathrm{g} / \mathrm{kg} \text { over } 5-40 \mathrm{~min} \\
\text { Infusion: } 0.3-5 \mu \mathrm{g} / \mathrm{kg} / \mathrm{min}\end{array}$ \\
Aminophylline & $52(47.3 \%)$ & $\begin{array}{l}\text { Bolus/load: } 5 \mathrm{mg} / \mathrm{kg} \text { over } 20-30 \mathrm{~min}(96.2 \%) \\
\text { Infusion: } 1 \mathrm{mg} / \mathrm{kg} / \mathrm{h}(62 \%)\end{array}$ & $\begin{array}{l}\text { Bolus load: } 10 \mathrm{mg} / \mathrm{kg}-200 \mathrm{mg} \text { (total) over } 30 \mathrm{~min} \\
\text { Infusion: } 0.5-1.0 \mathrm{mg} / \mathrm{kg} / \mathrm{h}\end{array}$ \\
\hline
\end{tabular}


Correction notice This article has been corrected since it was published Online First. The group 'the PERUKI network' has been added to the end of the author list.

Acknowledgements The following acted as PERUKI (http://www.peruki.org) site lead coordinators and data collectors for this element of the FESTIVA study. They were responsible for contributing information to the centres screening data for the 10 weeks. Royal Belfast Hospital for Sick Children (Steve Mullen and Elizabeth Dalzell), Birmingham Children's Hospital (Stuart Hartshorn), Royal Alexandra Children's Hospital. Brighton and Sussex University Hospital (Catherine Bevan), Bristol Royal Hospital for Children (Hannah Spires), The Noah's Ark Children's Hospital for Wales Cardiff (Zoe Roberts), Chelsea and Westminster Hospital (James Ross and Frances Blackburn), University Hospital Crosshouse Kilmarnock (Joanne Mulligan), Royal Derby Hospital (Gisela Robinson), Royal Hospital for Sick Children Edinburgh (Alastair Kidd), Guys and St Thomas NHS Foundation Trust Evelina (John Criddle), Royal Hospital for Sick Children Glasgow (Vince Choudhery, James Paton), University Hospitals of Leicester (Ffion Davies, Cat Bryceland), Lewisham and Greenwich NHS Trust (Jane Bayreuther), Royal Manchester Children's Hospital (Kaz Potier), North Manchester General Hospital (Andrew Rowland and Festus Madufor), Nottingham Children's Hospital (Clare Dieppe, Philip Miller), Derriford Hospital Plymouth (Jason Smith and Roz Squire), Royal Free (Shye Wei Wong), Barts and Royal London (Ami Parikh), Sheffield Children's Hospital (Derek Burke), University Hospital of Southampton (Jason Barling), St Mary's Hospital London (Ian Maconochie and Graeme Hadley), Sunderland (Niall Mullen) and Tallaght Hospital Dublin (Turlough Bolger).
Contributors CVEP and MDL conceived the evaluation. CVEP, MDL, IJMD, ROS, $\mathrm{NS}$ and IM developed the methodology and protocol and collected the data. Analysis and initial draft was by IM, CVEP and MDL. ROS, IJMD and NS provided further comment on the analysis and editing for the final submitted paper.

Competing interests None.

Provenance and peer review Not commissioned; externally peer reviewed.

\section{REFERENCES}

1 Jackson DJ, Sykes A, Mallia P, et al. Asthma exacerbations: origin, effect and prevention. J Allergy Clin Immunol 2011;128:1165-74.

2 British Thoracic Society and Scottish Intercollegiate Guidelines Network. British Guideline on the Management of Asthma: A National Clinical Guideline. British Thoracic Society and Scottish Intercollegiate Guidelines Network, revised January 2012. http://www.brit-thoracic.org.uk/guidelines/asthma-guidelines.aspx

3 Babl FE, Sheriff N, Borland M, et al. Paediatric acute asthma management in Australia and New Zealand: practice patterns in the context of clinical practice guidelines. Arch Dis Child 2008;93:307-12.

4 Mohammed S, Goodacre S. Intravenous and nebulised magnesium sulphate for acute asthma: systematic review and meta-analysis. Emerg Med J 2007;24:823-30.

5 Paton J. British Thoracic society Paediatric wheeze/Asthma audit report 2012. http:// www.britthoracic.org.uk/Portals/0/Audit\%20Tools/SummaryReports/Paediatric\% 20Asthma\%20Summary\%20Report2012\%20-\%20final.pdf (accessed Aug 2014). 